\title{
HASIL BELAJAR BIOLOGI DITINJAU DARI MODEL EXAMPLES NON EXAMPLES BERBANTUAN MULTIMEDIA LECTORA INSPIRE
}

\author{
Mhd. Rafi'i Ma'arif Tarigan ${ }^{1 *}$, Afrida Yanti Dalimunte ${ }^{2}$, Yuri Indri Yani ${ }^{3}$ \\ ${ }^{1}$ Sekolah Tinggi Ilmu Tarbiyah Hamzah Al-Fansuri Sibolga Barus \\ ${ }^{2}$ Sekolah Persatuan Amal Bakti (PAB) Medan Estate \\ ${ }^{3}$ Universitas Islam Negeri Sultan Syarif Kasim Riau \\ *rafiimagister8@gmail.com
}

\begin{abstract}
ABSTRAK
Penelitian ini bertujuan untuk mengetahui pengaruh Model Pembelajaran Examples non Examples menggunakan Multimedia Lectora Inspire terhadap hasil belajar biologi siswa pada materi Sistem Reproduksi yang dilaksanakan selama 2 bulan dengan menggunakan metode eksperimen semu. Data dalam penelitian ini termasuk penelitian kuantitatif yaitu berupa hasil belajar pada materi pokok Sistem Reproduksi. Teknik pengambilan sampel yang digunakan berupa simple ramdom sampling. Instrumen yang digunakan dalam bentuk tes yaitu pretest dan postest. Soal pretest dan postest disusun berdasarkan indikator dalam bentuk tes objektif dengan lima pilihan jawaban ( $a, b, c$, dan e). Analisis yang digunakan adalah Uji t. Hasil belajar siswa yang menggunakan Model Pembelajaran Examples non Examples Menggunakan Multimedia Lectora Inspire diperoleh nilai yang tuntas adalah sebanyak 27 siswa (79,41\%) dan yang tidak tuntas sebanyak 7 siswa (20,58\%) dengan nilai rata-rata 83,85 dan standar deviasi 7,73. Hasil uji hipotesis menggunakan uji $t$ diperoleh $t_{\text {hitung }}>t_{\text {tabel }}$ atau $11,68>1,69$ dengan taraf kepercayaan 0,05 maka $H_{a}$ diterima $H_{o}$ ditolak, sehingga dinyatakan bahwa ada pengaruh yang signifikan penggunaan Model Pembelajaran Examples non Examples Menggunakan Multimedia Lectora Inspire terhadap hasil belajar Biologi siswa pada materi Sistem Reproduksi di Kelas XI MIA MAS Proyek UNIVA Medan. Manfaat dari penelitian ini adalah untuk memberikan informasi kepada pendidik bahwa penggunaan model pembelajaran Examples non Example dengan menggunakan Multimedia Lectora Inspire efektif dalam meningkatkan hasil belajar biologi siswa dan disarankan bagi pendidik untuk dapat menerapkan model ini dalam proses pembelajaran.
\end{abstract}

Kata Kunci: Examples non Examples, Hasil Belajar, Lectora Inspire, Model Pembelajaran

\begin{abstract}
This research aims to determine the effect of Examples non Examples learning models using Multimedia Lectora Inspire on student biology learning outcomes on Reproductive System material which was carried out for 2 months using the quasi-experimental method. The data in this study include quantitative research in the form of learning outcomes on the subject matter of the Reproductive System. The sampling technique used is simple random sampling. The instruments used in the form of tests are pretest and posttest. The pretest and posttest questions are arranged based on indicators in the form of an objective test with five answer choices $(a, b, c$, and e). The analysis used is $t$ test. Student learning outcomes using Examples non Examples Learning Models Using Lectora Inspire Multimedia obtained complete scores as many as 27 students (79.41\%) and those who did not complete as many as 7 students (20.58\%) with an average score of 83.85 and standard deviation 7.73. The results of hypothesis testing using t test obtained tcount $>t$ table or 11.68> 1.69 with a confidence level of 0.05 then Ha accepted Ho is rejected, so that it is stated that there is a significant effect of using Learning Model Examples non Examples Using Multimedia Lectora Inspire on learning outcomes Biology of students on the material of the Reproductive System in Class XI MIA MAS UNIVA Medan Project. The benefit of this research is to provide information to educators that the use of Examples non Example learning model using Multimedia Lectora Inspire is effective in improving student biology learning outcomes and it is recommended for educators to be able to apply this model in the learning process.
\end{abstract}

Keywords: Examples non Examples, Learning Outcome, Lectora Inspire, Learning Model 


\section{PENDAHULUAN}

Tujuan pembelajaran setiap mata pelajaran di sekolah secara umum adalah untuk menyiapkan siswa agar dapat hidup dalam masyarakat sebagai manusia yang bermanfaat, yaitu mempunyai pengetahuan dan keterampilan dalam mengatasi masalahmasalah yang dihadapinya (Bahri et al., 2018; Zubaidah, 2016). Untuk mencapai tujuan tersebut guru perlu memperhatikan aspekaspek yang mempengaruhi kegiatan pembelajaran dalam merancang maupun melaksanakan proses pembelajaran agar dapat terlaksana dengan baik. Aspek-aspek tersebut antara lain adalah strategi pembelajaran, metode pembelajaran, model pembelajaran, teknik dan taktik pembelajaran. Sebagai salah satu aspek dalam kegiatan pembelajaran, Huda (2014) memaparkan bahwa model-model pembelajaran dirancang untuk tujuan-tujuan tertentu, pengajaran konsep-konsep informasi, cara berpikir, studi nilai-nilai sosial dan sebagainya dengan meminta siswa untuk terlibat aktif dalam tugas-tugas kognitif dan sosial tertentu.

Keaktifan siswa dalam proses pembelajaran dapat memberikan kesempatan kepada siswa untuk berpikir agar dapat mengenal dan memahami apa yang sedang dipelajarinya. Adanya interaksi antar siswa dan guru harus berjalan dengan baik untuk meningkatkan kualitas dalam pembelajaran. Kualitas pembelajaran suatu sekolah dapat dilihat dari segi proses dan hasil belajar. Sedangkan hasil belajar itu sendiri adalah kemampuan yang dimiliki siswa dalam menerima pengalaman belajarnya.

Permasalahan yang paling mendasar adalah ketidaktuntasan hasil belajar peserta didik. Ketidaktuntasan tersebut disebabkan karena dalam proses belajar mengajar, guru yang lebih aktif (teacher centered) dibandingkan peserta didik (student centered) sehingga para peserta didik tidak mampu berperan aktif dalam proses belajar mengajar di kelas (Tarigan et al., 2019). Permasalahan kedua adalah kurangnya variasi guru dalam mengajar. Guru selalu memberikan pembelajaran dengan metode ceramah sehingga membuat suasana di kelas menjadi jenuh, sehingga pemahaman peserta didik menjadi menurun (Sanjaya, 2011; Sartika 2015; Tarigan et al., 2020). Lalu, permasalahan ketiga adalah kurangnya fasilitas sarana dan prasana di sekolah tersebut. Paparan ini sejalan dengan pernyataan Tarigan et al., (2016) dan William \& Mary (2008) mengungkapkan bahwa lengkapnya sarana dan prasarana di sekolah akan menunjang kelancaran dalam proses belajar mengajar. Berdasarkan paparan masalah-masalah tersebut, solusi untuk mengatasinya adalah dilakukan pemilihan model pembelajaran yang tepat, yaitu pembelajaran yang harus melibatkan peserta didik untuk aktif sehingga peserta didik belajar dengan suasana yang menyenangkan (Tarigan et al., 2020).

Berdasarkan hasil observasi di sekolah Madrasah Aliyah Swasta Univa Medan melalui wawancara dengan guru bidang studi Biologi bahwa pembelajaran di sekolah tersebut sudah menggunakan Kurikulum 2013 (K13) yang dimana proses belajar mengajar sudah menggunakan pendekatan scientific approach sehingga menarik untuk mencoba memadu multimedia Lectora Inspire sebagai media pembelajaran dengan model Examples non Examples agar dapat meningkatkan hasil belajar siswa. Paparan ini sejalan dengan pernyataan Susanti (2014) mengungkapkan bahwa model pembelajaran Examples non Examples dengan menggunakan Power Point dapat meningkatkan hasil belajar siswa pada mata pelajaran IPA di SMP Negeri 2 Mojotengah. Fitriani dan Qurbania (2018) mengungkapkan bahwa model pembelajaran Examples non Examples dan Picture dan Picture dapat meningkatkan hasil belajar siswa di SMA Negeri 2 Sungai Raya.

Model pembelajaran ini menempatkan siswa ke dalam kelompok-kelompok kecil yang heterogen, dimana pembelajaran disajikan dalam bentuk gambar, diagram atau tabel yang sesuai dengan materi bahan ajar dan kompetensi dasar. Selain itu salah satu cara penyampaian materi juga dapat menggunakan 
multimedia pembelajaran. Dimana salah satu multimedia yang dapat digunakan adalah Lectora Inspire. Lectora Inspire ini merupakan software yang di dalamnya dapat menggabungkan file berbentuk flash, menggabungkan gambar serta video (Firmansyah \& Rusman, 2019; Komalasari, 2010; Mas'ud, 2012; Shalikhah, 2016).

Penggunaan model pembelajaran yang bervariasi dapat menghasilkan suasana belajar yang berbeda dan lebih bermakna bagi siswa (Arifin, 2012; Alisa et al., 2017; Wijanarko, 2017). Model pembelajaran yang menggunakan media dapat menuntun siswa untuk mampu mengembangkan keterampilan berpikir, serta meningkatkan keaktifan siswa secara keseluruhan dalam proses belajar mengajar (Haryanti, 2017). Dalam penelitiannya, Putera et al. (2016) menggunakan model pembelajaran Examples non Examples dengan menggunakan media berupa power point dan picture and picture. Sedangkan dalam penelitian ini model pembelajaran Examples non Examples diperbantukan dengan Multimedia Lectora Inspire agar dapat mempermudah pendidik dalam penyampaian materi pembelajaran serta memberikan motivasi dan menumbuhkan siswa aktif, mandiri serta dapat berpikir kritis (Nurhafni et al., 2019).

Penelitian ini bertujuan untuk mengetahui hasil belajar biologi siswa setelah menggunakan model pembelajaran Examples non Examples dengan Multimedia Lectora Inspire di Kelas XI MIA MAS Proyek UNIVA Medan. Dari hasil penelitian ini diharapkan dapat memberikan informasi kepada guru biologi dalam penggunaan model pembelajaran Examples non Examples dengan Multimedia Lectora Inspire.

\section{METODE}

Penelitian ini dilaksanakan di MAS Proyek UNIVA Medan. Penelitian ini berlangsung selama 2 bulan. Populasi dalam penelitian ini adalah seluruh siswa kelas XI MIA MAS Proyek UNIVA Medan yang berjumlah 66 orang dari 2 kelas.
Teknik pengambilan sampel dilakukan secara Simple Random Sampling dan sampel yang terpilih dalam penelitian ini yaitu kelas XI MIA $^{1}$ UNIVA Medan yaitu sebagai kelas yang diajar menggunakan model pembelajaran Examples non Examples menggunakan Multimedia Lectora Inspire.

Model pembelajaran Examples non Examples ditujukan untuk mengajarkan siswa dalam belajar memahami dan menganalisis sebuah konsep. Adapun sintaks pembelajaran Examples non Examples dapat dilakukan sebagai berikut. (1) guru mempersiapkan gambargambar sesuai dengan tujuan pembelajaran, (2) guru menempelkan gambar dipapan atau ditanyangkan lewat OHP atau proyektor, (3) guru membentuk kelompok-kelompok yang masing-masing terdiri dari 2-3 siswa, (4) guru memberi petunjuk dan kesempatan kepada setiap kelompok untuk memperhatikan dan menganalisis gambar, (5) mencatat hasil diskusi dari analisis gambar pada kertas, (6) memberi kesempatan bagi tiap kelompok untuk membacakan hasil diskusinya, (7) berdasarkan komentar atau hasil diskusi siswa, guru menjelaskan materi sesuai tujuan yang ingin dicapai, dan (8) kesimpulan (Lestiawan \& Johan, 2018).

Penelitian ini termasuk eksperimen semu (quasi eksperiment). Penelitian ini hanya menggunakan kelas eksperimen tanpa adanya kelas kontrol. Desain penelitian adalah rancangan eksperimen dengan one group pretest-posttest design dengan menggunakan kelas eksperimen yaitu model pembelajaran Examples non Examples menggunakan Multimedia Lectora Inspire dengan desain sebagai berikut.

Tabel 1. Desain Penelitian

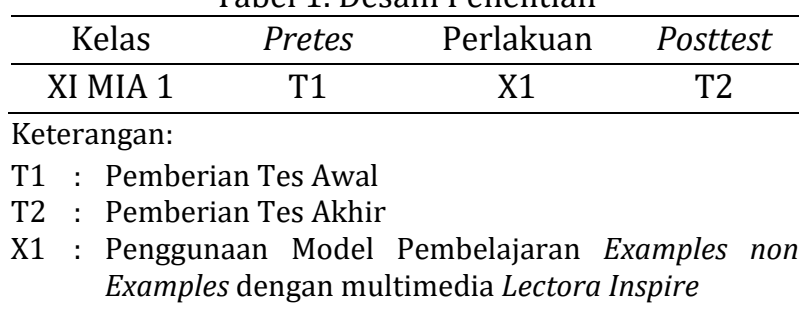

Instrumen yang digunakan untuk mengumpulkan data hasil belajar siswa adalah instrumen tes yang telah diuji validitas serta 
reliabilitasnya. Pretest berupa 20 butir soal pilihan berganda dengan lima opsi (a, b, c, d, e) di tiap butirnya. Penyusunan instrumen berdasarkan level kognitif taksonomi bloom yang terdiri dari C1, C2, dan C3.

Posttest diberikan sebagai data hasil belajar siswa yang diberikan setelah proses pembelajaran berlangsung. Tes ini diberikan untuk mengetahui sejauh mana hasil belajar siswa yang dijarkan dengan model pembelajaran Exampel non example dengan multimedia Lectora Inspire pada materi Sistem Reproduksi. Posttest berupa 30 butir soal pilihan berganda dengan lima opsi (a, b, c, d, e) di tiap butirnya. Pemilihan soal-soal dalam penelitian ini didasarkan pada tingkatan kemampuan kognitif yang terdapat dalam Taksonomi Bloom. Data yang telah didapatkan kemudian dianalisis menggunakan uji t.

\section{HASIL DAN PEMBAHASAN}

Hasil penelitian yang dilakukan terhadap siswa kelas XI MIA 1 UNIVA Medan yang berjumlah 34 siswa diperoleh data bahwa nilai tertinggi siswa pada pretest adalah 75 sebanyak 4 siswa dan nilai terendah adalah 55 sebanyak 5 siswa. Nilai pretest siswa yang tuntas sebanyak 4 siswa $(11,76 \%)$ dan yang tidak tuntas 30 siswa $(88,23 \%)$.

Tabel 2. Distribusi Frekuensi Nilai pre-test siswa kelas XI-MIA 1 MAS Proyek UNIVA Medan

\begin{tabular}{|c|c|c|c|c|c|c|}
\hline No & $\begin{array}{c}\text { Kelas } \\
\text { Interval }\end{array}$ & fi & $x i$ & $x i^{2}$ & fi.xi & fi. $x i^{2}$ \\
\hline 1 & $55-57$ & 5 & 56 & 3136 & 280 & 15680,00 \\
\hline 2 & $58-60$ & 4 & 59 & 3481 & 236 & 13924,00 \\
\hline 3 & $61-63$ & 0 & 62 & 3844 & 0 & 0,00 \\
\hline 4 & $64-66$ & 11 & 65 & 4225 & 715 & 46475,00 \\
\hline 5 & $67-69$ & 0 & 68 & 4624 & 0 & 0,00 \\
\hline 6 & 70-72 & 10 & 71 & 5041 & 710 & 50410,00 \\
\hline \multirow[t]{2}{*}{7} & $73-75$ & 4 & 74 & 5476 & 296 & 21904,00 \\
\hline & $\sum$ & 34 & & & 2237 & 148393,0 \\
\hline
\end{tabular}

Sementara pada hasil posttest diketahui bahwa nilai tertinggi siswa adalah 93 sebanyak 5 siswa dan nilai terendah adalah 67 sebanyak 1 siswa. Nilai posttest siswa yang tuntas sesuai KKM adalah sebesar 27 siswa $(79,41 \%)$ dan yang tidak tuntas 7 siswa (20,58\%) dengan nilai-nilai rata-rata posttest $83,85 \pm 7,73$.
Tabel 3. Distribusi Frekuensi Nilai pre-test siswa kelas XI-MIA 1 MAS Proyek UNIVA Medan

\begin{tabular}{ccccccc}
\hline No & $\begin{array}{c}\text { Kelas } \\
\text { Interval }\end{array}$ & $\mathrm{Fi}$ & $\mathrm{Xi}$ & $\mathrm{xi}^{2}$ & fi.xi & fi.xi $^{2}$ \\
\hline 1 & $67-71$ & 3 & 69 & 4761 & 207 & 14283 \\
\hline 2 & $72-76$ & 4 & 74 & 5476 & 296 & 21904 \\
\hline 3 & $77-81$ & 5 & 79 & 6241 & 395 & 31205 \\
\hline 4 & $82-86$ & 6 & 84 & 7056 & 504 & 42336 \\
\hline 5 & $87-91$ & 11 & 89 & 7921 & 979 & 87131 \\
\hline 6 & $92-96$ & 5 & 94 & 8836 & 470 & 44180 \\
\hline & $\sum$ & 34 & & & 2851 & 241039 \\
\hline
\end{tabular}

\section{Uji Persyaratan Data}

Uji normalitas data nilai hasil belajar siswa yang menggunakan pendekatan pembelajaran penggunaan model pembelajaran Example non example dengan multimedia Lectora Inspire pada pre-test diperoleh Lhitung $=0,1333$ mengunakan taraf $\alpha=0,05$ dan $N=34$, diperoleh dari daftar nilai kritis untuk uji Liliefors harga Ltabel $=0,1519$ ternyata Lhitung $<$ Ltabel, yaitu $0,1333<0,1519$ diperoleh kesimpulan bahwa data hasil pretest berdistribusi normal.

Uji normalitas data nilai hasil belajar siswa yang menggunakan pendekatan pembelajaran penggunaan model pembelajaran Examples non Examples dengan multimedia Lectora Inspire pada posttest diperoleh $\mathrm{L}_{\text {hitung }}=0,1075$ mengunakan taraf $\alpha=0,05$ dan $\mathrm{N}=34$, diperoleh dari daftar nilai kritis untuk $U j i$ Liliefors harga $\mathrm{L}_{\text {tabel }}=0,1519$ ternyata $\mathrm{L}_{\text {hitung }}<$ $\mathrm{L}_{\text {tabel, }} \quad$ yaitu $\quad 0,1075<0,1519$ diperoleh kesimpulan bahwa data hasil posttest berdistribusi normal.

Hasil uji homogenitas data pada taraf signifikan $\alpha=0,05$ diperoleh $F_{\text {hitung }}<F_{\text {tabel }}$ yaitu $(1,62<1,88)$, sehingga dapat disimpulkan bahwa populasi yang menjadi penelitian merupakan populasi yang homogen dan telah memenuhi syarat untuk dilakukan uji hipotesis.

Berdasarkan penelitian terhadap normalitas dan homogenitas bahwa telah diketahui persyaratan analisis data dalam penelitian ini adalah berdistribusi normal dan dari variasi populasi yang homogen. Selanjutnya akan dilakukan uji hipotesis dapat diperoleh thitung 11,68 dan uji thitung yang dilakukan pada taraf nyata $\alpha=0.05$ atau 0,95 . 
Hasil perhitungan tersebut menunjukkan bahwa $t_{\text {hitung }}>\mathrm{t}_{\text {tabel }}$ atau 11,68 $>1,69$ maka $\mathrm{H}_{\mathrm{o}}$ ditolak dan $\mathrm{H}_{a}$ diterima, yang dinyatakan ada pengaruh yang singnifikan penggunaan model Examples non Examples menggunakan Multimedia Lectora Inspire Terhadap hasil Belajar Siswa pada materi sistem reproduksi di kelas XI MIA MAS Proyek UNIVA Medan.

Hasil pengujian kovariat menyatakan bahwa Ho ditolak dan Ha diterima, sehingga disimpulkan bahwa ada pengaruh yang signifikan dari model pembelajaran Examples non Examples menggunakan Multimedia Lectora Inspire terhadap hasil belajar siswa pada materi sistem reproduksi di kelas XI MIA MAS Proyek UNIVA Medan.

Dari hasil uji normalitas dapat diketahui bahwa data berdistribusi normal dimana Lhitung dan $\mathrm{L}_{\text {tabel }}$ maka $0,1333<0,1519$ atau $\mathrm{L}_{\text {hitung }}<\mathrm{L}_{\text {tabel. }}$ Dari hasil uji homogenitas data diketahui bahwa $F_{\text {hitung }}<F_{\text {tabel }}$ yaitu $(1,62<1,88)$. Sehingga dapat disimpulkan bahwa data adalah homogen.

Setelah itu dilakukan uji t hasil pre-test dan post-test diproleh nilai thitung pada taraf nyata $\propto=0,05$ yaitu $t_{\text {hitung }}=11,40$ dan $t_{\text {tabel }}=1,694$, maka $t_{\text {hitung }}>t_{\text {tabel }}=11,68>1,69$ sehingga $H_{a}$ diterima dan $\mathrm{H}_{\mathrm{o}}$ ditolak, maka ada pengaruh yang signifikan penggunaan model penerapan Examples non Examples menggunakan Multimedia Lectora Inspire terhadap hasil belajar siswa pada materi Sistem Reproduksi di kelas XI MIA I MAS Proyek UNIVA Medan.

Hasil penelitian ini menunjukkan bahwa Model Examples non Examples yang menggunakan Multimedia Lectora Inspire membuat proses pembelajaran lebih menarik dan kontekstual. Hal itu dikarenakan siswa dihadapkan pada masalah-masalah dekat dengan kehidupan mereka sehari-hari. Paparan ini sesuai dengan pernyataan Rahmadani (2019) yang mengungkapkan bahwa peserta didik dihadapkan pada situasi kehidupan nyata, mencoba membuat pertanyaan terkait masalah dan memungkinkan munculnya berbagai solusi untuk menyelesaikan permasalahan. Melalui gambargambar serta video yang berkaitan dengan konteks kehidupan mereka yang berkaitan dengan materi yang diajarkan, sehingga siswa akan mampu memecahkan masalah yang terdapat pada gambar dan video. Jadi siswa tidak hanya menerima penjelasan tetapi juga mengamati, dan memahami gambar setara video dengan teman kelompoknya, hal ini tentu akan lebih memudahkan siswa untuk memahami materi dan mengingatnya lebih lama. Paparan ini sejalan dengan pernyataan Shalikhah (2016) mengungkapkan bahwa dengan menggunakan Lectore Inspire, materi pelajaran didesain semenarik mungkin, dapat menampilkan video, gambar-gambar animasi yang berhubungan dengan materi pelajaran, serta guru dapat membuat materi uji di dalamnya. Proses pembelajaran akan lebih menyenangkan dan bermakna sehingga berpengaruh pada peningkatan prestasi belajar peserta didik.

Selain itu, Hamdani (2011) menyebutkan bahwa Examples non Examples adalah metode belajar yang menggunakan contoh-contoh berupa gambar, foto, kasus untuk mendorong siswa mampu berpikir kritis dalam memecahkan permasalahan yang disajikan. Model pembelajaran Examples non Examples dapat ditunjukan untuk mengajarkan defenisi suatu konsep (Susanti, 2014). Huda (2014) juga menerangkan bahwa Examples non Examples merupakan strategi pembelajaran yang menggunakan gambar sebagai media untuk menyampaikan materi pelajaran.

\section{PENUTUP}

Kesimpulan yang bisa diambil pada penelitian ini adalah bahwa model pembelajaran Examples non Examples yang menggunakan multimedia Lectora Inspire ini memberikan pengaruh yang signifikan terhadap hasil belajar siswa kelas XI MIA I MAS Proyek UNIVA Medan. Hasil ini sesuai dengan kelebihan dari model tersebut bahwa model pembelajaran Examples non Examples yang menggunakan multimedia Lectora Inspire untuk menyampaikan materi dapat membuat suasana pembelajaran menjadi menyenangkan dan kontekstual. Hal ini dikarenakan melalui gambar-gambar serta video yang disajikan 
membuat siswa dihadapkan pada masalahmasalah dekat dengan kehidupan mereka sehari-hari.

Adapun yang menjadi saran dari penelitian ini adalah bagi guru dan calon guru khususnya bidang studi pendidikan biologi agar kiranya bersedia mencoba menggunakan Model Pembelajaran Examples non Examples yang menggunakan multimedia Lectora Inspire dan melibatkan integrasi aktif ide-ide baru dengan konsep pembelajaran yang ada. Selain itu, disarankan juga untuk melakukan penelitian lanjutan agar penerapan model pembelajaran ini dapat tercapai dan hasil belajar siswa dapat lebih baik dan kontekstual. Penulis mengakui banyak memiliki kekurangan dalam penelitian ini, sehingga perlu dilengkapi atau disempurnakan pada tahap penelitian selanjutnya.

\section{REFERENSI}

Alisa, Y., Yennita \& Irawati, S. (2017). Peningkatan aktivitas dan hasil belajar siswa SMP menggunakan model problem based learning. Diklabio: Jurnal Pendidikan dan Pembelajaran Biologi, 1(1), 117-124.

Arifin, Z. (2012). Evaluasi pembelajaran. PT Remaja Rosdakarya.

Bahri, A., Putriana, D., \& Idris, S.I. (2018). Peran PBL dalam meningkatkan keterampilan pemecahan masalah biologi. Jurnal Sainsmat, 7(2), 114-124.

Firmansyah, R.M.G., \& Rusman. (2019). Efektivitas media pembelajaran lectore inspire dalam meningkatkan hasil belajar peserta didik pada mata pelajaran biologi. Pedagogia Jurnal Ilmu Pendidikan, 17(1), 8092.

Fitriani, Y., \& Qurbania, M. (2018). Komparasi model examples non examples dan picture and picture terhadap hasil belajar pada sub materi tulang SMA Negeri 2 Sungai Raya. Jurnal Bioeducation, 1(1), 15-21.

Hamdani. (2011). Strategi belajar mengajar. Pustaka Setia.

Haryanti, D.Y. (2017). Model problem based learning membangun kemampuan berpikir kritis siswa sekolah dasar. Jurnal Cakrawala Pendas, 3(2), 57-63.
Huda, M. (2014). Model-model pengajaran dan pembelajaran. Pustaka Pelajar.

Komalasari, K. (2010). Pembelajaran kontekstual konsep dan aplikasi. Refika Aditama.

Lestiawan, F., \& Johan, B.A. (2018). Penerapan metode pembelajaran example non example untuk meningkatkan keaktifan dan hasil belajar dasar-dasar pemesinan. Jurnal Tamam Vokasi, 6(1), 98-106.

Mas'ud, M. (2012). Membuat multimedia pembelajaran dengan lectora. Pustaka Shonif

Nurhafni, Erna, M., \& Susilawati. (2019). Developing learning media based lectora inspire on chemical equilibrium. International Journal of Science and Applied Technology, 4(2), 1-6.

Putera, C. C. P., Agustini, K., \& Sugihartini, N. (2016). Studi komparatif penggunaan model pembelajaran picture and picture dan example and non example terhadap minat dan hasil belajar siswa. Kumpulan Artikel Mahasiswa Pendidikan Teknik Informatika, 5 (2), 1-10.

Rahmadani. (2019). Metode penerapan model pembelajaran problem based learning. lantanida joernal, 7 (1), 75-86.

Sartika, D. (2015). Pengaruh model pembelajaran berbasis proyek, penemuan terbimbing terhadap pengetahuan biologi, sikap ilmiah dan keterampilan proses sains siswa SMA Diponegoro Kisaran [Tesis]. Pascasarjana Unimed.

Sanjaya, W. (2011). Strategi pembelajaran berorientasi standar proses pendidikan. Rineka Cipta.

Shalikhah, D.N. (2016). Pemanfaatan aplikasi lectora inspire sebagai media pembelajaran interaktif. Cakrawala, 11 (1), 101-115.

Susanti, R. (2014). Pembelajaran model examples non examples berbantuan power point untuk meningkatkan hasil belajar IPA. Jurnal Pendidikan IPA Indonesia, 3 (2), 123127.

Tarigan, M.R.M., Binari, M., Sudibyo, M. (2016). Pengaruh model pembelajaran penemuan terbimbing (guided discovery), kooperatif tipe jigsaw terhadap kemampuan berpikir tingkat tinggi, keterampilan proses sains, dan sikap ilmiah biologi siswa pada materi sistem pencernaan makanan di kelas XI SMA Negeri 1 Sibolga [Tesis]. Pascasarjana Unimed.

Tarigan, M.R.M., Purnama, A.D., Munir, M., \& Azwar, E. (2019). Pengaruh model active 
Jurnal Biolokus: Jurnal Penelitian Pendidikan Biologi dan Biologi Vol.4(1)

debate terhadap hasil belajar siswa pada materi ekosistem di kelas X Madrasah Aliyah Swasta Proyek Univa Medan. Jurnal Biolokus, 2(1), 139-145.

Tarigan, M.R.M., Manalu, A.W., Tanjung, H.E., Saragih, J.S., Ula, A. (2020). Pengaruh model snawball throwing terhadap hasil belajar siswa pada materi sistem pertahanan tubuh di SMA Swasta Medan. Jurnal Biolokus, 3(2), 313-319.

Wijanarko, Y. (2017). Model pembelajaran make a match untuk pembelajaran IPA yang menyenangkan. Jurnal Taman Cendekia, 1(1), 52-59.

William., \& Mary. (2008). The walls speak: The interplay of quality facilities, school climate, and student achievement. Journal of Educational Administration, 46(1), 55-73.

Zubaidah, S. (2016). Keterampilan abad ke-21, keterampilan yang diajarkan melalui pembelajaran. Seminar nasional pendidikan dengan tema isu-isu strategis pembelajaran MIPA abad 21, Program Studi Pendidikan Biologi STKIP Persada Khatulistiwa SintangKalimantan Barat. 